\title{
THE SIZE OF THE LEFT ATRIUM IN CONDITIONS OTHER THAN MITRAL VALVE DISEASE
}

\author{
BY \\ B. W. COBBS, * J. P. SHILLINGFORD, † AND R. E. STEINER \\ From the Departments of Medicine and Radiology, Hammersmith Hospital, Postgraduate Medical School of London \\ Received February 11, 1957
}

The relatively frequent observation that patients with hypertensive cardiovascular disease had $\mathrm{X}$-ray evidence of left atrial enlargement led us to do a combined radiological and post-mortem study of this chamber, and the purpose of this paper is to show that considerable enlargement of the left atrium may occur in the absence of mitral valve disease.

\section{Historical NoTE}

The association of left atrial enlargement with mitral disease was clearly appreciated in the writings of Corvisart (1806). The displacement of the esophagus by the enlarged atrium was noted in 1910 by Kovács and Stoerk. In 1920 Kreuzfuchs introduced the use of barium in the œsophagus as a means of outlining cardiac and other intrathoracic structures. Within a few years the technique was securely established as a means of detecting the left atrial enlargement of mitral stenosis (Rigler, 1929). Somewhat similar X-ray abnormalities were soon noted in other conditions by Parkinson (1936) and Rigler (1933). In 1937 Babey summarized these reports and added other examples, which included patients with atrial septal defect, coarctation of the aorta, essential hypertension, aortic valve disease, thyrotoxicosis, and prolonged atrial fibrillation: the majority of his patients had evidence of cardiac failure. A few were examined post-mortem and in some, but not all of his cases the left atrial enlargement was thought to have been confirmed pathologically. Epstein and Schwedel (1938), in a combined radiographic and necropsy study, which included 54 cases of non-valvular heart disease, found evidence of left atrial enlargement by inspection in 25 at necropsy; there was a good correlation of pathological and fluoroscopic data. More recently, Evans (1952) has pointed out that radiological evidence of left atrial enlargement often occurs in constrictive pericarditis. Kjellberg (1955) has noted the left atrial enlargement of ventricular septal defect and persistent ductus arteriosus in children.

None of these observers, however, attempted to confirm the fact of left atrial enlargement by any quantitative method. Stephen Hales in 1733 was probably the first to measure the heart cavities directly: using a standard pressure, he filled the hearts of animals with molten wax, the volume of which was then determined by its displacement of water. Hiffelsheim and Robin in 1864 used the same method to measure the capacity of the human heart chambers: they found the normal left atrium to contain 100-130 c.c. Hochrein in 1927 using water at a pressure of $8 \mathrm{~cm}$. found an average capacity of $140 \mathrm{ml}$. for the normal left atrium in 30 cases. Friedman in 1951 noted that total heart volumes calculated from their data were significantly higher than those given by modern radiographic estimates, and he concluded that deficiencies in the test conditions had dilated some or all of the heart cavities beyond their usual state in life.

\footnotetext{
* Work done while in receipt of a grant from the U.S. Public Health Service.

$\dagger$ Member of the Scientific Staff of the Medical Research Council.

2L 


\section{METHODS}

Of 163 hearts studied from 6 to 72 hours after death, 53 were controls and 110 included those with rheumatic, hypertensive, coronary, and pulmonary heart disease. In addition to routine examination at the necropsy the heart was removed intact with at least a quarter inch of the pulmonary veins and suspended upright in a lukewarm water bath: the left ventricle and atrium were distended by two rubber condoms attached to glass burettes by stiff rubber sleeves (Fig. 1). The condom in the ventricle was filled with water to close the mitral valve; the atrial condom was then filled to a pressure of $30 \mathrm{~cm}$. of water. Four measurements of the volume of water used to distend the atrium to this pressure were made and usually agreed to within $5 \mathrm{ml}$.

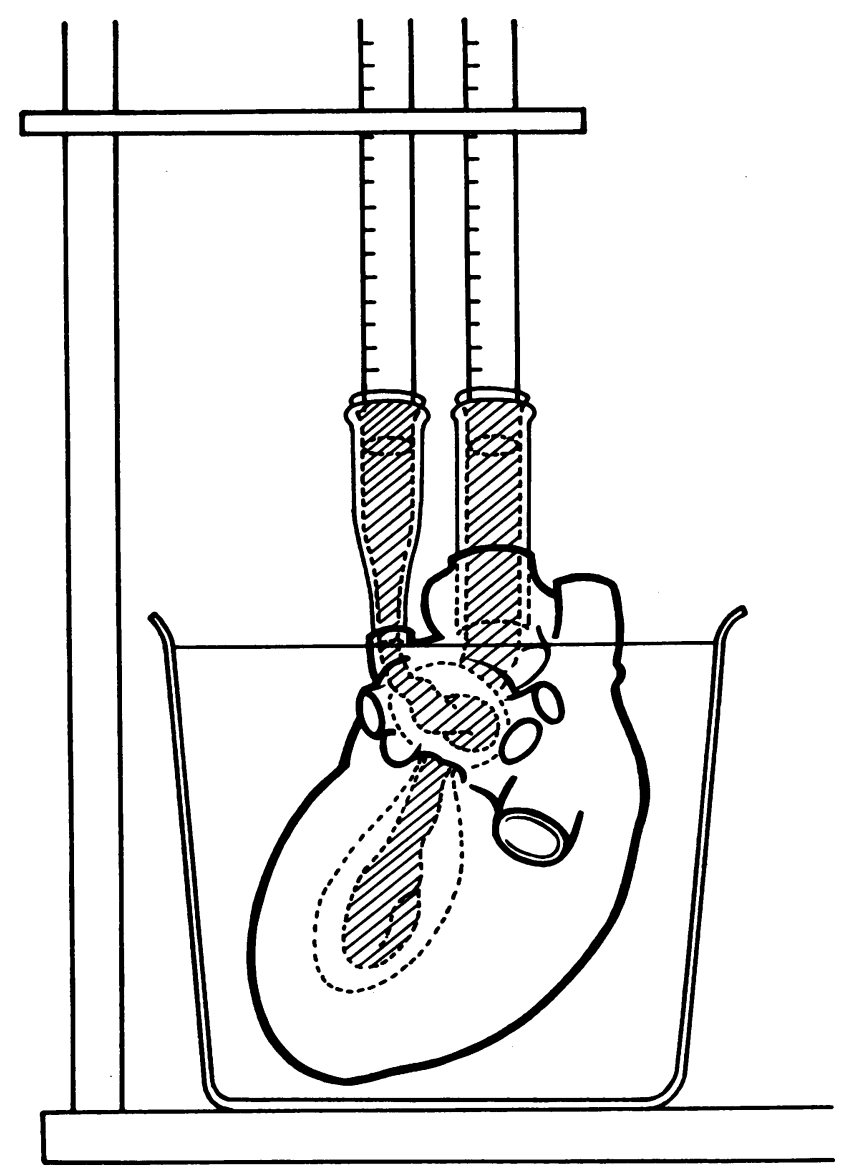

FIG. 1.-The method of measuring left atrial size at autopsy.

Error Limits of Post-mortem Measurements. Measurement of the left atrial size were made at 8, 12, 24 hours and daily after death in six hearts kept moist with normal saline at $40^{\circ} \mathrm{F}$. In two an additional measurement was made within 2 hours of death. No significant change of volume was found in the serial measurements from 8 hours after death, although a slight diminution of volume appeared in the first few hours probably due to rigor mortis.

A comparison was made between recorded volumes with and without a rubber condom: the introduction of the latter appeared to reduce slightly the measured volume but could be compensated by an increase in the pressure from 18 to $30 \mathrm{~cm}$. of $\mathrm{H}_{2} \mathrm{O}$. This arbitrary pressure which was adequate to distend the atrium was used throughout and no attempt made to equate it to the left atrial pressure in life. 
The left atrial size was assessed radiologically by the standard criteria outlined by Rigler(1929) and Evans (1936). Reliance was placed on the deflection of the barium-filled æesophagus in the oblique and lateral projections and the left atrial outline visible through the heart shadow on the right side; 45 patients were studied within six weeks of death and, independently of the post-mortem measurements results classified as normal, probably enlarged, and enlarged. Ten had mitral heart disease and 35 included hypertensive, aortic, coronary arterial, and pulmonary heart disease.

\section{RESULTS}

The size of the atrium in the control group appeared to be related to the total body height and correction was made for this by adjusting all the observations to the mean height by a regression equation. Fig. 2 shows the volumes in the normal male and female group. In the former the size varied from 60 to $115 \mathrm{ml}$. and in the latter from 60 to $90 \mathrm{ml}$.

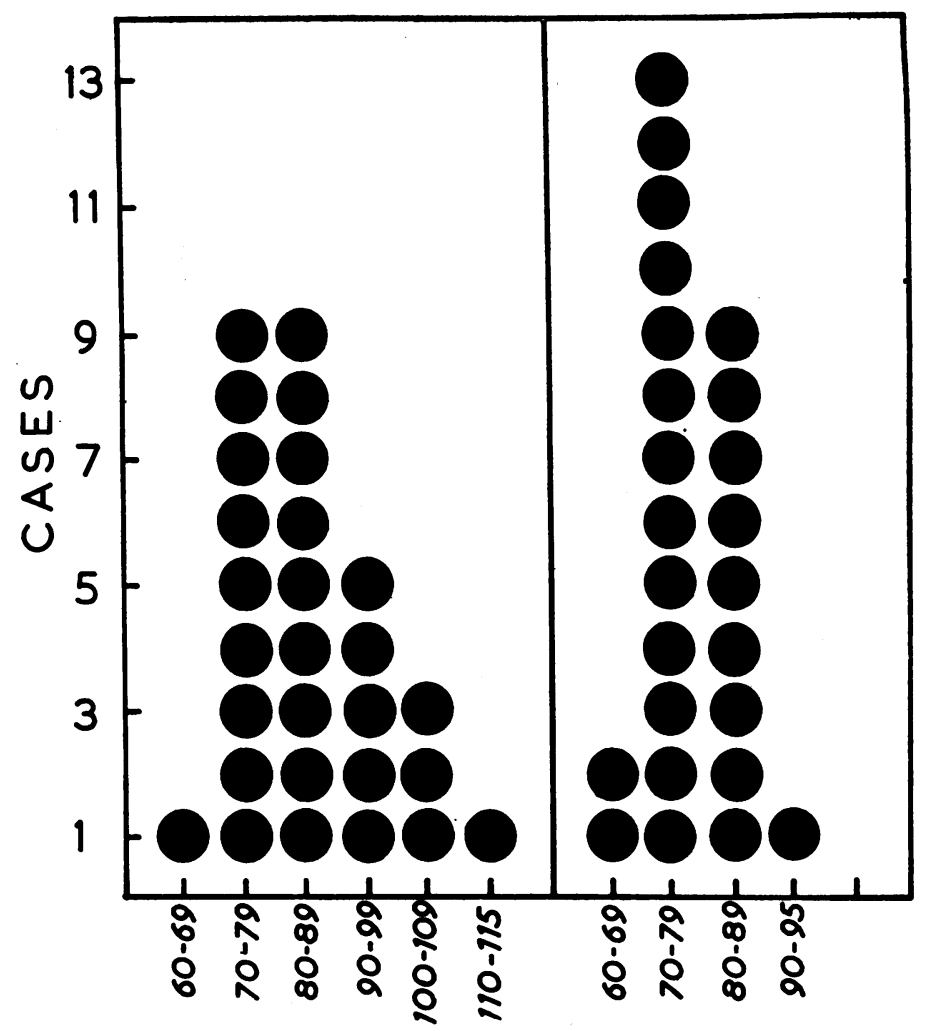

Fig. 2.-The left atrial volume (ml.) in 53 normal hearts at necropsy. Men on the left, women on the right. Each dot represents one case (corrected for height of patient).

Fig. 3 and 4 summarize the left atrial volumes at necropsy in 110 patients with heart disease. The bottom line gives the normal distribution curve. Each of the disease groups has been arbitrarily divided into four subgroups on clinical grounds. (1) Severe disease but no evidence of cardiac failure. (2) Mild disease with no evidence of failure. (3) Cardiac disease with terminal failure of duration of three weeks or more before death. (4) Those in whom cardiac failure was a terminal event, less than three weeks or had occurred in the past for short periods only. 
It will be seen that the biggest atria occurred in those with disease of the mitral valve and in one case reached $400 \mathrm{ml}$. In patients who in life had other forms of heart disease the atrium in many cases was enlarged up to and over $150 \mathrm{ml}$. which is about twice the average normal size. In many of these heart failure was established but not in all.

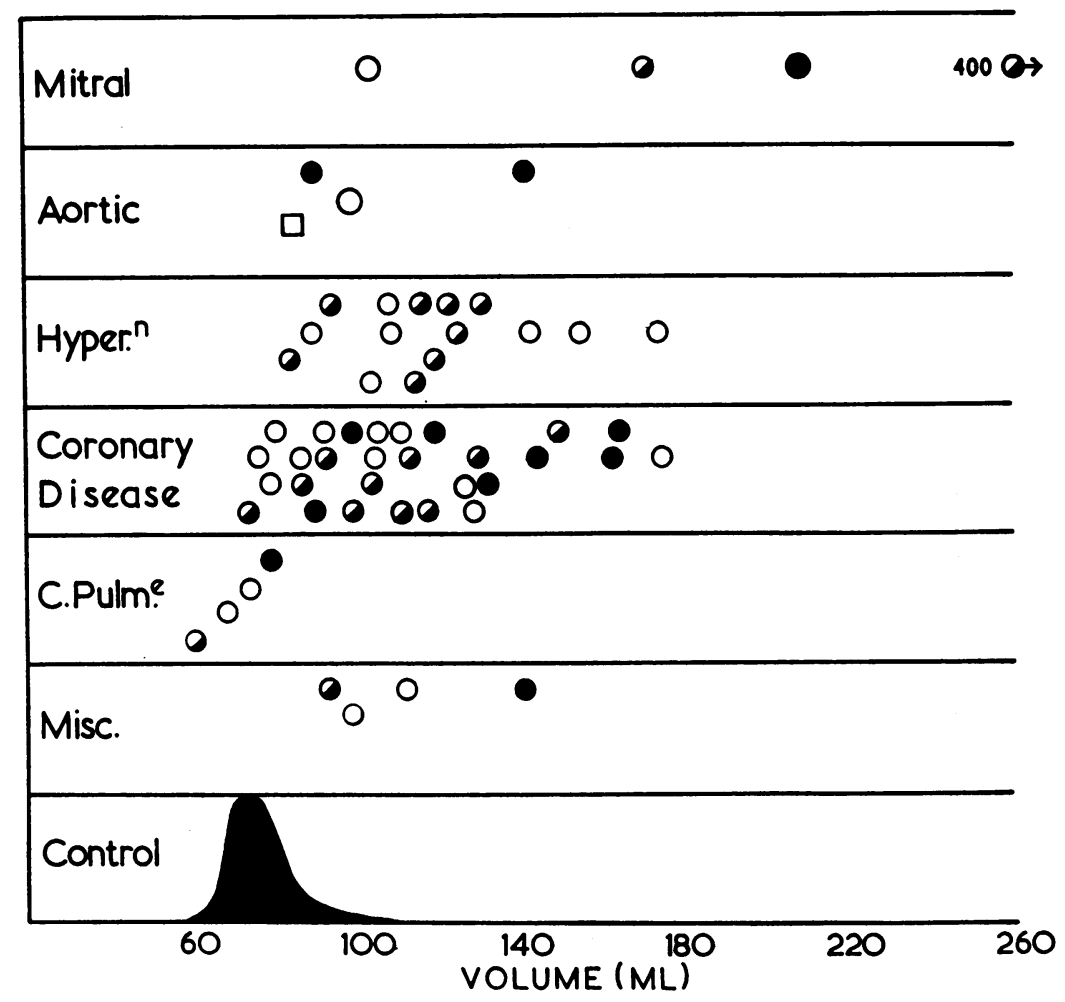

FIG. 3.-The left atrial volumes at necropsy in 59 men dying of various cardiac conditions. Control distribution curve on bottom line. (See Fig. 4 for explanation of symbols.)

Of the 45 patients examined radiologically 22 had a normal atrium confirmed in 21 by necropsy while in 1 the atrium was probably enlarged. In 4 the atrium was probably enlarged radiologically but at autopsy 1 was normal and 3 were enlarged. In the 19 patients with definite radiological left atrial enlargement 1 was normal in size at necropsy, 2 were probably enlarged, and 16 certainly enlarged. The latter included mitral, aortic, hypertensive, and coronary arterial disease (Fig. $5,6,7,8)$. Left atrial enlargement could usually be diagnosed radiologically when the volume was over $120 \mathrm{ml}$. as measured at necropsy.

\section{Discussion}

The pathological and radiological results show that left atrial enlargement may occur in all types of cardiac disease in which the left side of the heart is involved. Although our pathological studies show that this increase is not as great as with severe mitral disease the volume may be over twice normal in such conditions as hypertensive or ischæmic heart disease. Myocardial failure is often found in this group with enlarged atria but not necessarily so; it is probably reasonable to postulate that the cause of enlargement in hypertensive disease is partly due to left atrial hypertension and, with the development of failure, to generalized cardiac dilatation. 


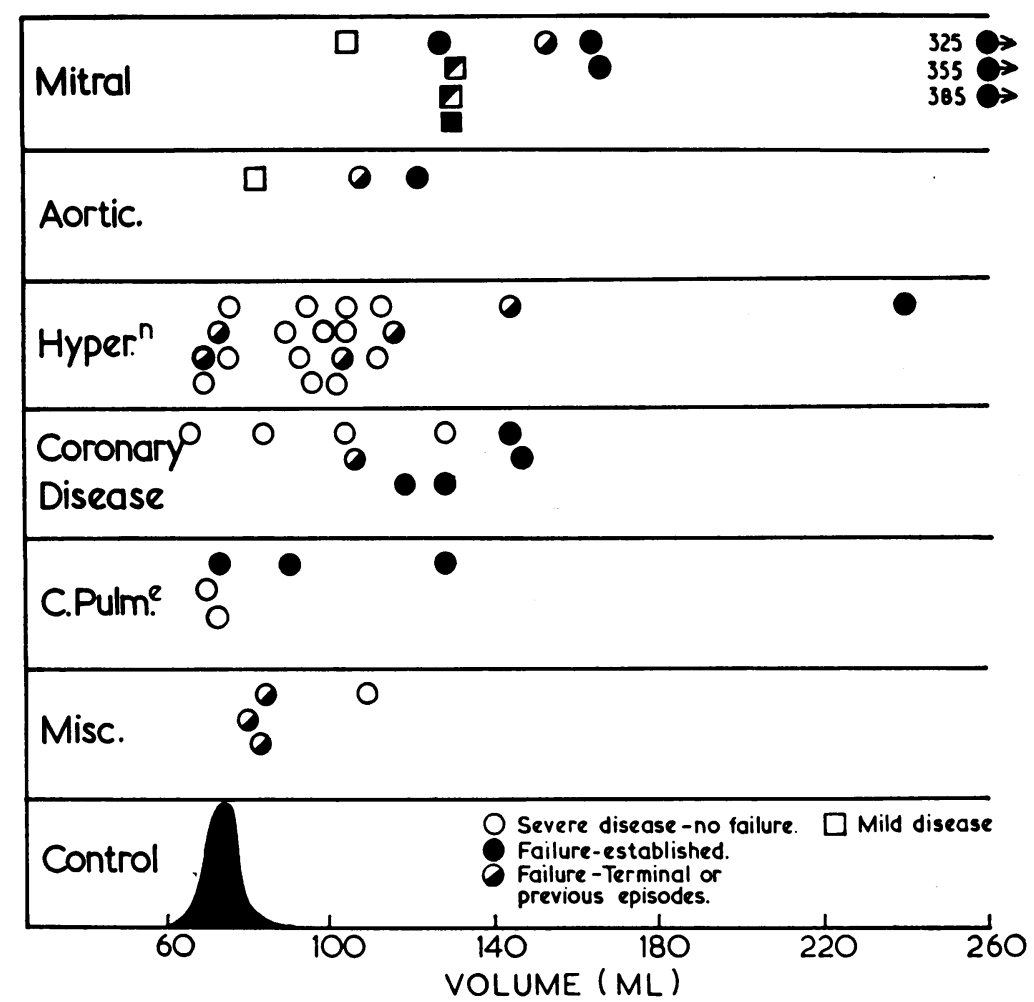

Fig. 4.-The left atrial volumes at necropsy in 51 women dying of various cardiac conditions. (Control distribution curve on bottom line.)

There was good correlation between the radiological findings of atrial enlargement and those found at necropsy.

Unequivocal radiological evidence of enlargement usually occurred when the atrial volume at death measured $120 \mathrm{ml}$. or more and in view of this it is unlikely that the signs of enlargement are due merely to displacement by the left ventricle.

These results give strong support to the criteria of radiological assessment of left atrial size laid down by Parkinson (1936) and Evans (1936). In assessing the left atrial impression on the œsophagus by an enlarged atrium the oblique projections are the conventional choice, but in our experience and from the results of the present study the left lateral projection is as reliable, which is in agreement with Soloff and Zatuchni (1956).

The double contour sign of an enlarged left atrium along the right cardiac border, although very useful as further indication of left atrial enlargement, is only convincing if the atrium is of such size that the œsophageal impression is quite definite and in itself diagnostic. The results also indicate that very slight left atrial enlargement may not always be demonstrable by radiological methods; nor can one distinguish left atrial enlargement due to mitral valve disease from that seen in other conditions such as hypertension or ischæmic heart disease, except by judgment made from the appearances of other cardiac chambers and the pulmonary vessels.

\section{SUMMARY}

To determine the normal size of the left atrium and its size in subjects dying from various types of cardiac disease, 163 hearts have been examined at necropsy. 


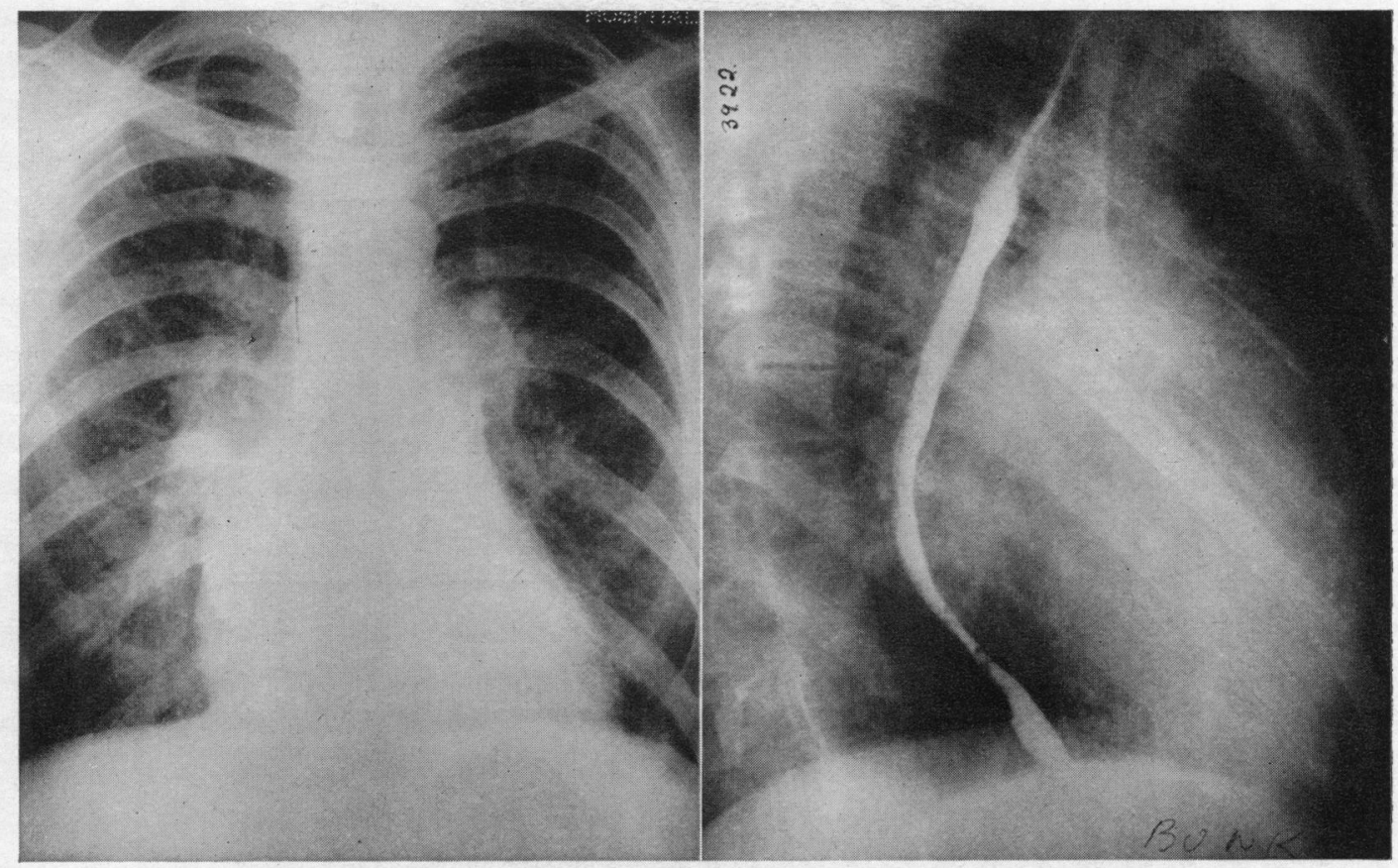

Fig. 5.-Man, aged 36, with mitral stenosis. Postero-anterior and first oblique projections demonstrated considerable left atrial enlargement. Left atrial volume at necropsy: $209 \mathrm{ml}$.

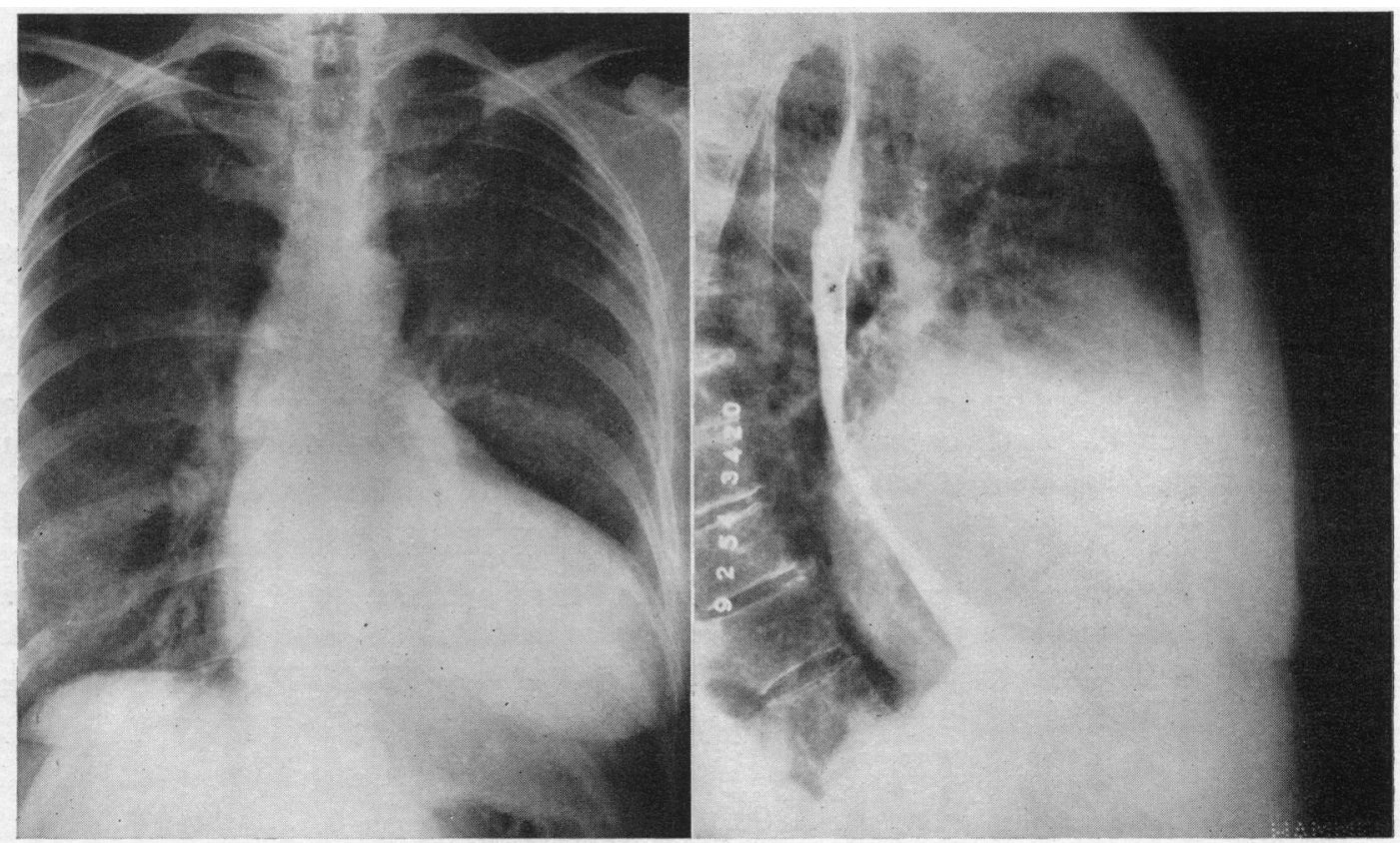

FIG. 6.-Woman, aged 53, with aortic stenosis. Posterior and lateral radiographs demonstrated considerable left ventricular and some left atrial enlargement. Volume of left atrium at necropsy: $124 \mathrm{ml}$. 


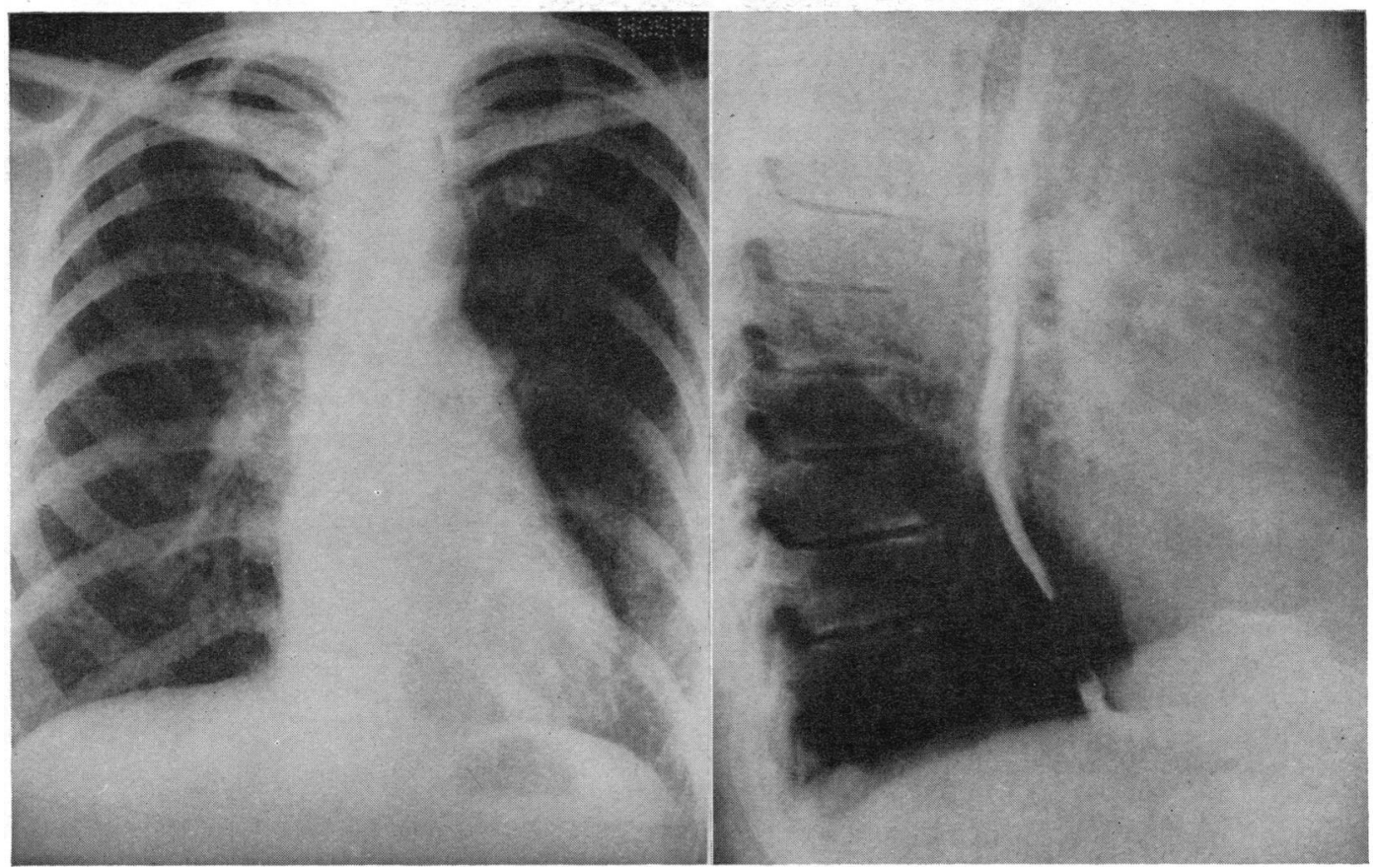

FIG. 7.-Man, aged 44, with essential hypertension. Posterior and lateral radiographs. There is evidence of slight left atrial enlargement. Volume of left atrium at necropsy: $123 \mathrm{ml}$.

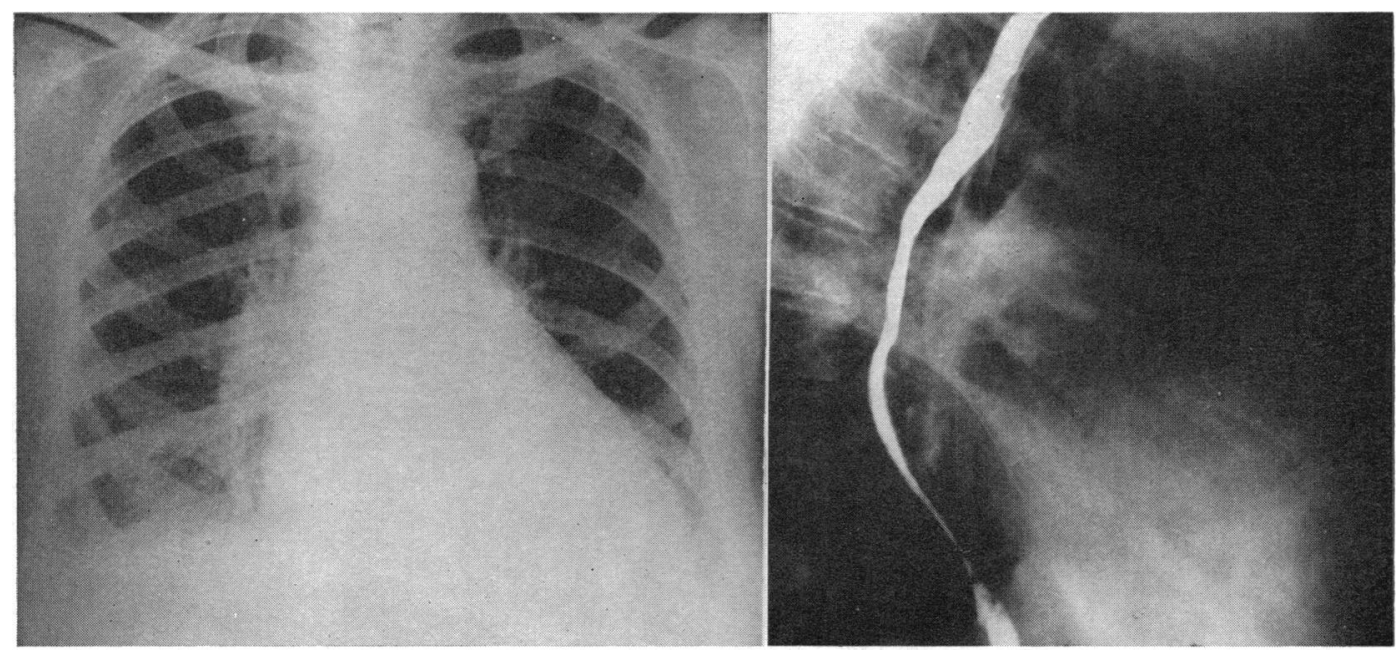

FIG. 8.-Woman, aged 58, with ischæmic heart disease and slight mitral incompetence. Posterior and lateral radiographs demonstrated general cardiac enlargement with definite left atrial enlargement. Atrial volume at necropsy: $145 \mathrm{ml}$. 
These results have been compared with the radiological findings in life.

Although the hearts with mitral valve lesions show the greatest left atria, considerable enlargement may be demonstrated by radiological and post-mortem examinations in those patients who have hypertension, coronary arterial disease, or aortic valve lesions. Although atrial enlargement is present in these in the absence of cardiac failure it is more common when generalized cardiac dilatation has occurred.

\section{REFERENCES}

Babey, A. (1937). Amer. Heart J., 13, 228.

Corvisart, J. N. (1806). Essai sur les Maladies et les Lésions Organiques du Caeur et des Gros Vaisseaux. MéquignonMarvis, Paris.

Epstein, B. S., and Schwedel, J. B. (1938). Amer. Heart J., 15, 317.

Evans, W., and Jackson, F. (1952). Brit. Heart J., 14, 53.

Friedman, C.-E. (1951). Acta med. scand., Suppl. 257.

Hales, S. (1733). Statical Essays. Containing Hamostaticks or an Account of Some Hydraulick and Hydrostatical Experiments made on Blood and Blood Vessels of Animals. T. Woodward, London.

Hiffelsheim, - , and Robin, C. (1864). J. Anat., Paris, 1, 413.

Hochrein, M. (1927). Arch. exp. Path. Pharmak., 124, 343.

Kjellberg, S. R., Mannheimer, E., Rudhe, U., and Jonsson, B. (1955). Diagnosis of Congenital Heart Disease. Yearbook Publishers, Chicago.

Kovács, F., and Stoerk, O. (1910). Wien. klin. Wschr., 23, 1471.

Kreuzfuchs, S. (1920). Med. Klinik., 16, 36.

Parkinson, J. (1936). Lancet, 1, 1392.

Rigler, L. G. (1929). Amer. J. Roentgenol., 21, 563.

(1933). Radiology, 20, 463.

Soloff, L. A., and Zatuchni, J. (1956). Amer. J. Med., 21, 551. 